\title{
Modeling and simulation of three phases cascaded H-bridge grid-tied PV inverter
}

\author{
Swetapadma Panigrahi, Amarnath Thakur \\ Department of Electrical and Electronics Engineering, NIT Jamshedpur, 831014, India
}

\begin{tabular}{l}
\hline \hline Article Info \\
\hline Article history: \\
Received May 23, 2018 \\
Revised Aug 11, 2018 \\
Accepted Nov 22, 2018 \\
\hline Keywords: \\
Fuzzy Logic Controller (FLC) \\
Maximum power point tracking \\
(MPPT) \\
Solar array \\
Three phase seven level cascaded \\
H-bridge inverter \\
\hline
\end{tabular}

\begin{abstract}
In this paper a control scheme for three phase seven level cascaded H-bridge inverter for grid tied PV system is presented. As power generation from PV depends on varing environmental conditions, for extractraction of maximum power from PV array, fuzzy MPPT controller is incorporated with each PV array. It gives fast and accurate response. To maintain the grid current sinusoidal under varying conditions, a digital PI controller scheme is adopted. A MATLAB/Simulink model is developed for this purpose and results are presented. At last THD analysis is carried out in order to validate the performance of the overall system. As discussed, with this control strategy the balanced grid current is obtained keeping THD values with in the specified range of IEEE-519 standard.
\end{abstract}

Copyright () 2019 Institute of Advanced Engineering and Science. All rights reserved.

Corresponding Author:

Swetapadma Panigrahi,

Department of Electrical and Electronics Engineering,

NIT Jamshedpur, 831014, India

Email: dipa.tat@gmail.com

\section{INTRODUCTION}

In recent year there is a huge demand of renewable energy sources instead of conventional one. Among these sources solar energy is the most emerging one [1, 2]. It does not need any fuel cost for maintenance or emit any noise becaming the most popular one. To integrate it with utility grid application of power electronics is essentially needed. Higher power applications require high DC voltage levels. Hence new topology has been evolved such that it can be directly connected to the grid with less switching actions. Multilevel inverter is the best solution for this purpose. Higher the voltage level, better is the sinusoidal output obtained with less harmonics content. Among the various topologies developed [3] cascaded H-bridge multilevel inverter is gaining the popularity as in this configuration individual voltage control can be possible as each H-bridge is feed by isolated solar panel [4]. This configuration has the advantages of (a) less complexity (b) usage of less number of components (c) no usage of diodes or capacitors for clamping.

The amount of power generated from a PV array depends upon its operating voltage that depends on the incident radiations and temperature. Different MPPT controllers have been developed in order to track the utmost power from PV panel that is independent of the enviornmental conditions. There are different literatures based on comparison of different maximum power point tracking algorithms used in PV system [5-7]. However, designing of controller play a very vital part in solar energy conversion system Several control techniques have been developed for current and voltage control of grid via cascaded-bridge multilevel inverter. In [8] a power weighted based multi input multi output control strategy is proposed to improve the current loop performance. A novel control strategy using robust and adaptive sliding-mode (SM) controller for a cascaded two-level inverter (CTLI)-based grid-connected photovoltaic (PV) system is proposed in [9]. A fuzzy logic based MPPT controller for grid tied application is proposed in this paper to enhance its energy efficiency under varing environmental conditions. Moreover, digital PI controller is proposed to balance the grid current under such condition. 


\section{RESEARCH METHOD}

This paper proposes a grid tied PV array connected to three phase seven level multilevel inverter. Generally, two types of control structure are adopted in grid-tied applications:

a. MPPT control: It aims to extract the utmost power from PV array.

b. Inverter control: It aims to control

1) Active power and reactive power that is injected into the grid.

2) Constant DC bus voltage.

3) Power level at the grid side.

\subsection{Simulation of PV array}

A PV cell converts the light energy extracted from sun into electrical energy. Current/voltage terminal characteristic for PV cell is mathematically described as [10, 11]:

$$
I=I_{p v}-I_{0}\left[\exp \left(\frac{\left(V+R_{S} I\right)}{V_{t} a}\right)-1\right]-\frac{V+R_{S} I}{R_{P}}
$$

where $V$ is terminal voltage of solar cell, $I$ is terminal current of solar cell, $\mathrm{I}_{\mathrm{pv}}$ is photo generated current (varies directly with irradiance), $I_{0}$ is saturation current due to diffusion mechanism, $V_{t}$ is threshold voltage, $a$ is diode quality factor, $R_{S}$ is cell series resistance, $R_{P}$ is cell shunt resistance. Solar cell equivalent circuit is shown in Figure 1. In this paper a PV panel of $185 \mathrm{~W}$ is taken. The various specifications of this model are presented in Table 1.

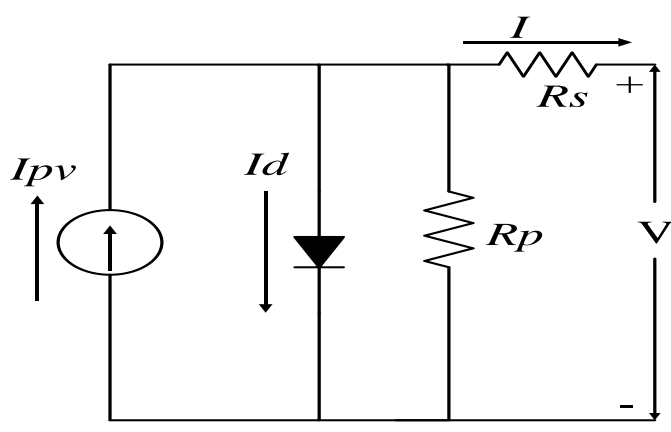

Figure 1. Solar cell equivalent circuit

Table 1. Parameters of adjusted model CHSM5612M (BL)-185 solar models at nominal operating condition

\begin{tabular}{ccc}
\hline Parameters & Variables & Values \\
\hline Maximum MPP Current & $I_{m p}$ & $5.09 \mathrm{~A}$ \\
Maximum MPP Voltage & $V_{m p}$ & $36.38 \mathrm{~V}$ \\
Maximum power obtained & $P_{\text {max.m }}$ & $185 \mathrm{~W}$ \\
Short circuit current & $I_{s c}$ & $5.39 \mathrm{~A}$ \\
Open circuit voltage & $V_{o c}$ & $45.12 \mathrm{~V}$ \\
diode quality factor & $a$ & 1.0141 \\
cell shunt resistance & $R_{p}$ & $836.88 \Omega$ \\
cell series resistance, & $R_{s}$ & $0.637 \Omega$ \\
Number of series connected cell & $N_{c e l l}$ & 72 \\
\hline
\end{tabular}

\subsection{Fuzzy MPPT}

Soft computing techniques offer a prime solution to solve the nonlinear problem. A FLC is a rule base algorithm that provides fast and flexible operation. MPPT tracking of PV panel is one of the toughest work as the voltage and current of PV panel varies according to temperature and incident light on it. The controller design for fuzzy inference system decides optimal performance of the system. But for rule base designing, expert knowledge of the system is essentially needed [12]. Generally working of FLC is based on three steps: fuzzification, inference fuzzy rules and defuzzication for tracking the utmost power.

\subsubsection{Fuzzification}

It is a process in which linguistic values are assigned with membership function values. seven different subsets, that are: NB (Negative Big), NM (negative medium), NS (Negative Small), ZE (Zero), PS (Positive small), PM (Positive Medium), PB (Positive Big) are used. Error $e$ and change in error $\Delta e$, sampled at time $k$ are taken as input variables.

where, $e=\frac{P_{p v(k)}-P_{p v(k-1)}}{V_{p v(k)}-V_{p v(k-1)}}$

$$
\Delta e=e(k)-e(k-1)
$$


The instantaneous power of the photovoltaic generator is $P_{p v(k)}$ and the voltage of the PV is denoted by $V_{p v(k)}$. Triangular membership function is considered and based on the system modeling the input scaling factors are designed with in the range specified in Figure 2.

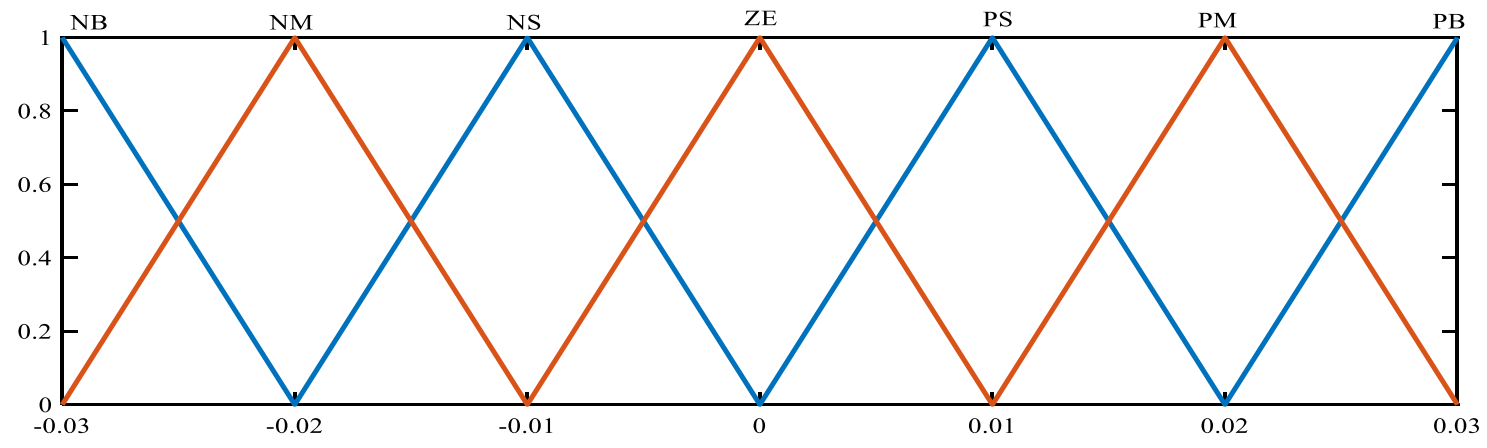

Membership functions for input $e$
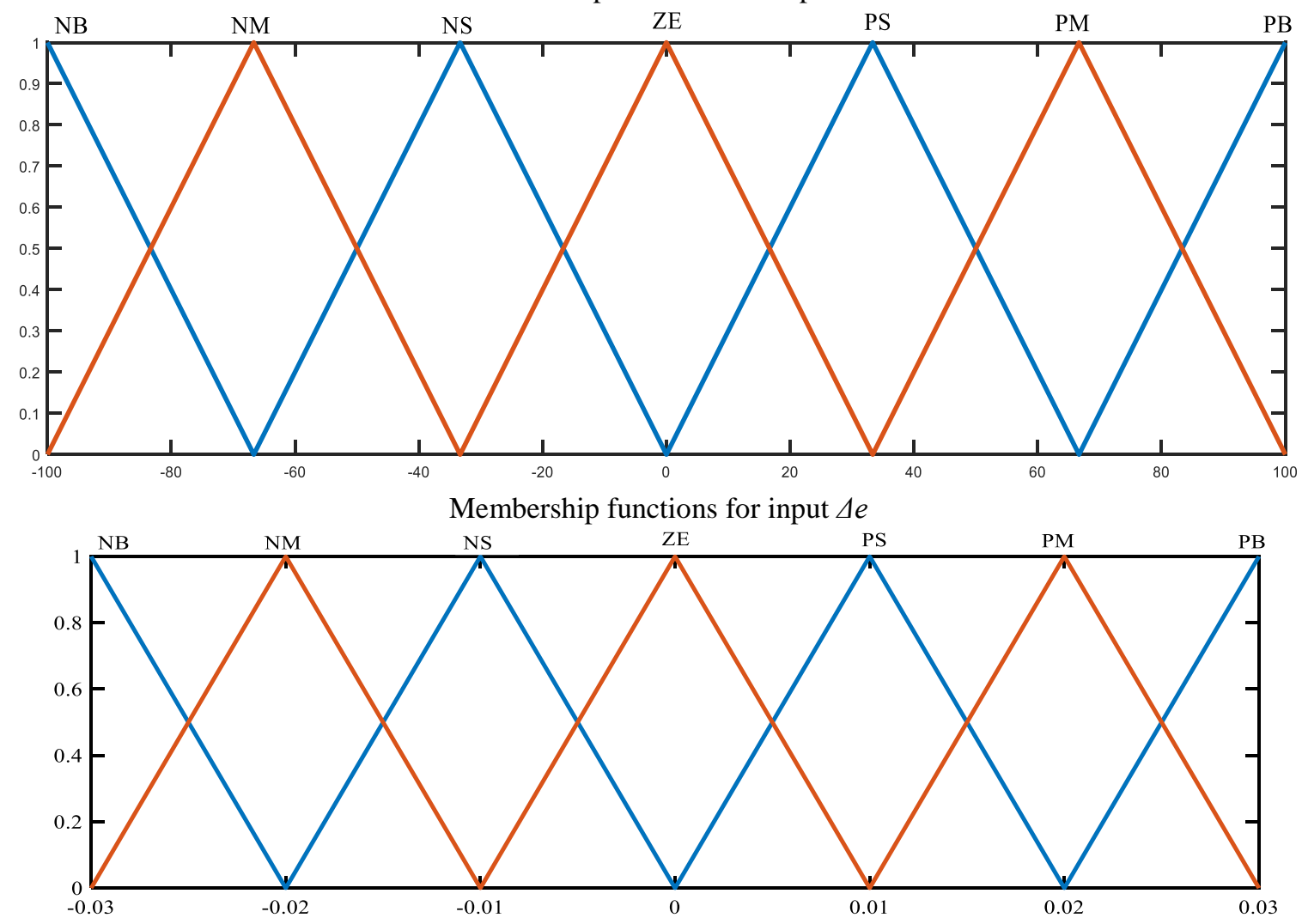

Membership functions for output $d \boldsymbol{\alpha}$.

Figure 2. Fuzzy input and output membership functions

\subsubsection{Inference system}

Fuzzy inference system mainly consists of fuzzy rule base and fuzzy implication. Based on the membership function rule base of following format is written:

If ( $x_{i}$ is $A_{i}$ and $y_{j}$ is $B_{j}$ ) then $z_{k}$ is $C_{k}$

where $x_{i}$ is error $(e), A_{i}$ is its linguistic value, $y_{j}$ is the change in error $(\Delta e), B_{j}$ is its linguistic value, $z_{k}$ is its optimum duty cycle and $C_{k}$ is its linguistic value. In this paper Max-Min method is used. 


\subsubsection{Defuzzification}

To satisfy the plant requirement the non-fuzzy variables are obtained by this process. Hence centre of gravity method is considered for this purpose. In this paper, the irradiation level is changed from 800 to $600 \mathrm{~W} / \mathrm{m}^{2}$ at $0.008 \mathrm{sec}$ and again change from 600 to $1000 \mathrm{~W} / \mathrm{m}^{2}$ at $0.015 \mathrm{sec}$. In order to track maximum power from PV system; the membership functions used are shown in Figure 3 and rule base is shown in Table 2.

Table 2. Fuzzy rule base for proposed system

\begin{tabular}{cccccccc}
\hline Error $(e)$ & & & & & & \\
\hline NB & NB & NB & NB & NB & NM & NS & ZE \\
NM & NB & NB & NB & NM & NS & ZE & PS \\
NS & NB & NB & NM & NS & ZE & PS & PM \\
ZE & NB & NM & NS & ZE & PS & PM & PB \\
PS & NM & NS & ZE & PS & PM & PB & PB \\
PM & NS & ZE & PS & PM & PB & PB & PB \\
PB & ZE & PS & PM & PB & PB & PB & PB \\
\hline
\end{tabular}

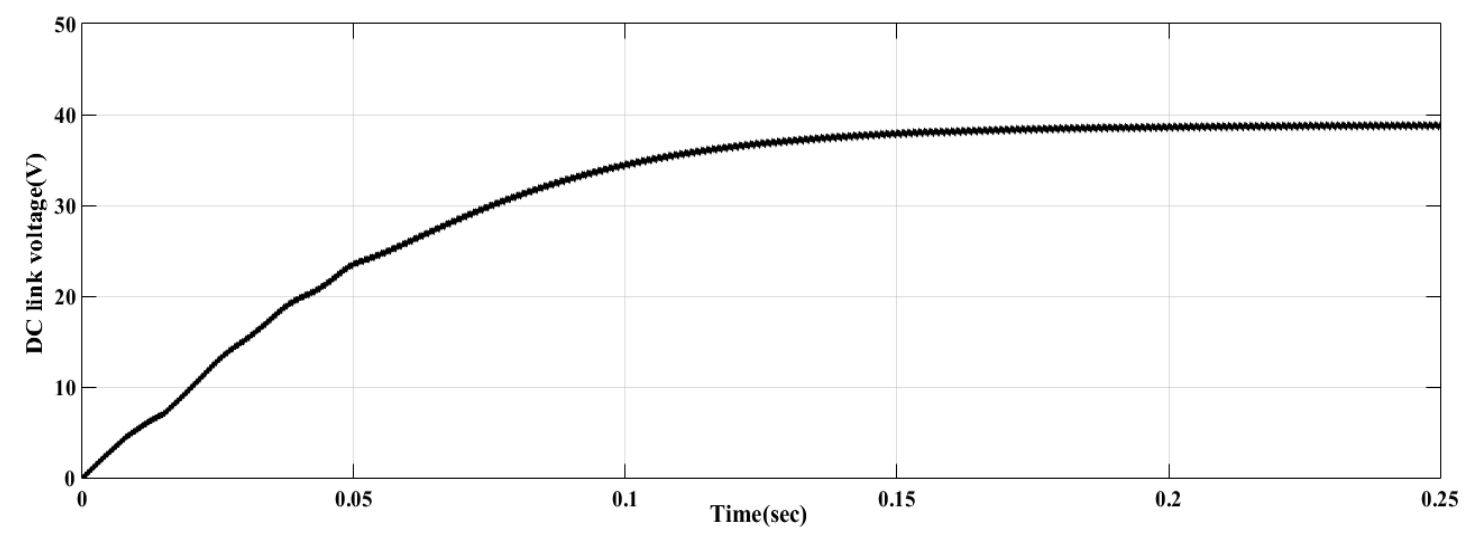

Figure 3. DC link voltage obtained from fuzzy MPPT controller

\section{CASCADED H-BRIDGE INVERTER TOPOLOGY}

The main purpose of multilevel inverter is to obtain a sinusoidal voltage from different voltage levels. A cascaded H-bridge is formed by series combination of several H-bridges with separate dc sources like PV panels in it. In Figure 4, $n$-level cascaded H-bridge inverter configuration is shown. The output phase voltage is obtained by sum of $n$ inverter outputs. With different switching combinations of $\mathrm{S}_{1}, \mathrm{~S}_{2}, \mathrm{~S}_{3}$ and $\mathrm{S}_{4}$ and $\mathrm{S}_{4}$, the output voltages $v_{d c}, 0, \frac{\mathrm{v}_{\mathrm{dc}}}{2}, 0$ and $-\frac{\mathrm{v}_{\mathrm{dc}}}{2}-v_{d c}$ are obtained. Turning on switches $S_{1}$ and $S_{4}$, output voltage $v_{d c}$ is obtained. Turning on $\mathrm{S}_{2}$ and $\mathrm{S}_{3}$ and $\mathrm{S}_{3}$ yield voltage $-v_{d c}$. When all the three switches are off zero output voltage is obtained [13].

A seven level CHB inverter produces the output voltage values (levels) with respect to negative terminal of the capacitors. If $n$ represents the number of step of phase voltage with respect to the negative terminal of the inverter, then the number of stages between two phases across load $k$ is represented as,

$$
k=2 n+1
$$




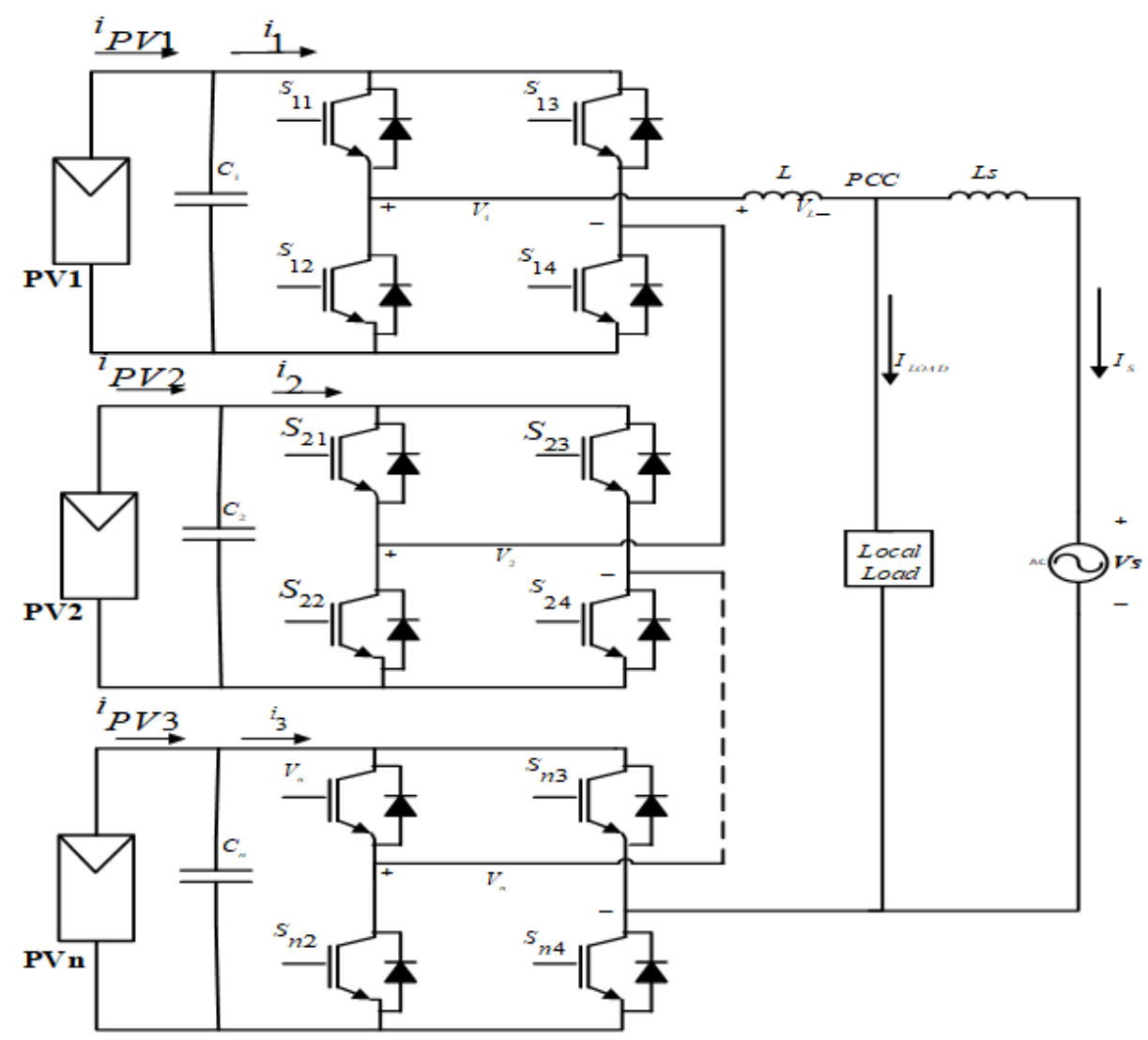

Figure 4. Configuration of single phase grid-connected PV system

Each H-bridge produces seven levels: $-3 v_{c},-2 v_{c},-\mathrm{v}_{c}, 0, v_{c}, 2 v_{c}, 3 v_{c}$, where $v_{c}$ is the DC-link voltage The output voltage can be represented by the upcoming equations:

$$
\begin{aligned}
& V_{H 1}=\left(S_{11}-S_{13}\right) v_{c 1}=\mathrm{P}_{1} v_{c 1} \\
& V_{H 2}=\left(S_{21}-S_{23}\right) v_{c 1}=\mathrm{P}_{2} v_{c 2}
\end{aligned}
$$

where $\mathrm{S}_{\mathrm{XX}}$ represents the switching state or it can be $\mathrm{ON}, 0$ or OFF. $S_{1}$ and $\mathrm{S}_{2} \mathrm{P}_{1}$ andP $\mathrm{P}_{2}$ represent the discrete values having the values of $-1,0,+1$. For linearization, continuous switching functions $S_{1}$ and $S_{2}[-1,1]$ are taken in place of the functions $\mathrm{P}_{1} \mathrm{P}_{1}$ and $\mathrm{P}_{2} \mathrm{P}_{2}[8,9]$. (3) represent the dynamic behavior of the system that is represented as:

$$
\begin{aligned}
& \frac{d i_{s}}{d t}=\frac{1}{L}\left(S_{1} v_{C 1}+S_{2} v_{C 2}-R i_{s}-v_{s}\right) \\
& \frac{d v_{C 1}}{d t}=\frac{1}{C_{1}}\left(i_{P V 1}-S_{1} i_{s}\right) \\
& \frac{d v_{C 2}}{d t}=\frac{1}{C_{2}}\left(i_{P V 2}-S_{2} i_{s}\right)
\end{aligned}
$$

\section{INVERTER CONTROL}

The layout of inverter control is shown in Figure 5. The reference DC bus generated by Fuzzy MPPT is compared with the actual DC bus voltage and error is passed through PI controller that generates the current reference in synchronous reference frame attached at grid voltage vector. 


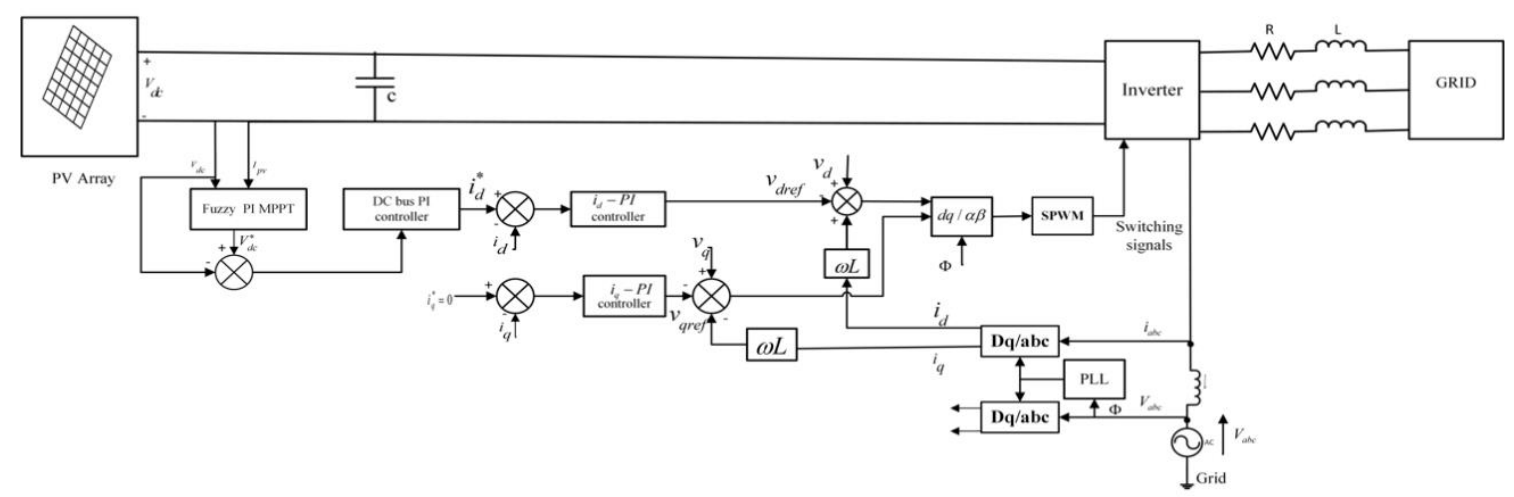

Figure 5. Layout of inverter control system

In order to maintain a power factor up to unity $Q_{\text {ref }}$ is set to be zero.After the inverse park transformation the reference signals for PWM are generated. These switching signals are the pulses to switch on the multilevel inverter.

\subsection{Digital PI control algorithm}

A digital PI control algorithm is implemented in MATLAB/Simulink software in order to maintain the injected grid current sinusoidal under rapidly changing atmospheric conditions. Fuzzy logic controller is used to extract the maximum power from each PV array. The PI controller is feed with instantaneous current error. The integral term in the PI controller improves the tracking by reducing the instantaneous error between the reference and the actual current [14].

\section{Mathematical expression:}

In continuous time domain the PI algorithm is expressed as,

$$
u(t)=K_{p} e(t)+K_{i} \int_{\tau=0}^{t} e(\tau) d \tau
$$

where; $u(t)=$ control signal

$e(\tau)=$ error signal

$t=$ time variable in continuous time domain

$\tau=$ calculus variable of integration

$K_{p}=$ proportional-mode control gain

$K_{i}=$ integral-mode control gain

The expression (4) is transferred to digital form with the use of Trapezoidal sum approximation. In discrete form it can be expressed as:

P term can be expressed as:

$$
K_{p} e(t)=K_{p} e(k)
$$

I term can be expressed as:

$$
K_{i} \int_{\tau=0}^{t} e(\tau) d \tau \square K_{i} \sum_{i=0}^{k} \frac{h}{2} e[(i)+e(i-1)]
$$

where $t=k * h$

$h$ : sampling time

$k$ : discrete time value, $k=0,1,2,3 \ldots$. 
Hence the new controller gain can be defined as: $K_{i}=K_{i} \frac{h}{2}$. Hence the digital PI controller can be expressed in the form:

$$
u(k)=K_{p} e(k)+K_{i} \sum_{i=0}^{k}[e(i)+e(i-1)]
$$

While designing the controller, the saturation of control signal and limitation of integral mode antiwindup is very much necessary. If there is a saturation in controller output, the integral-mode control term will go on increasing without producing any corresponding controller output. Hence plant response will not enhance. Progressively, the integral can be very large, taking more time to reduce once the sign of error signal changes its sign. It causes a large transient overshoot and undershoot along with large settling time. Hence in order to overcome this issue, an integral-mode windup is added having a saturation limit. The scheme is depicted in Figure 6. After tuning the digital PI controller the $K_{P}$ and $K_{i}$ values are determined.

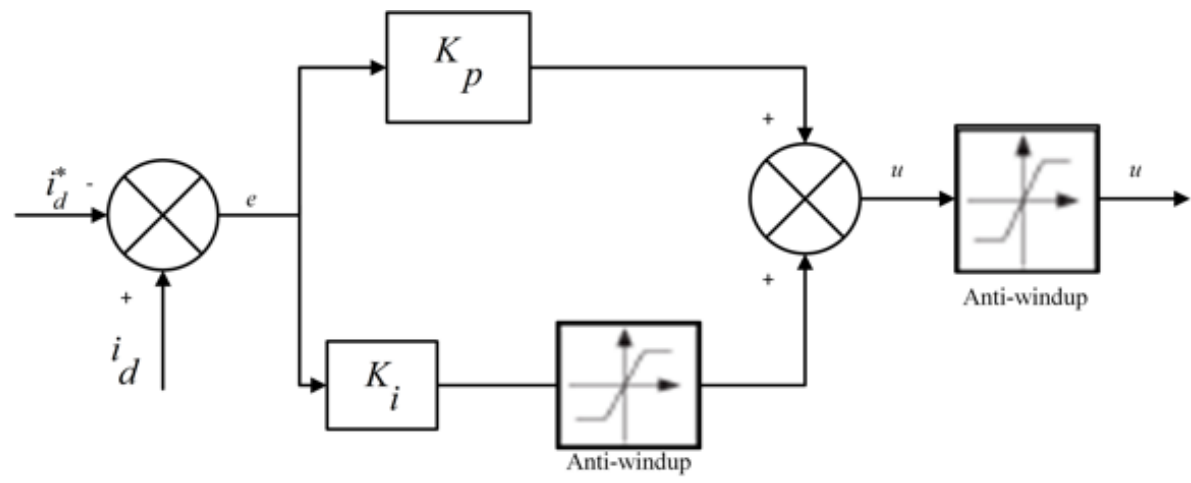

Figure 6. Digital PI control scheme

\subsection{Phase shifted modulation scheme}

There are different modulations techniques proposed for switching of multilevel inverters. Among which PS-PWM is most popularly used to produce PWM control signals for switching of the inverters. In PSPWM all the triangular carriers are having with the same frequency and same peak-peak amplitude and a phase shift is made among any two immediate carrier waves. For $m$ Voltage levels, there is need of $(m-1)$ carrier signals and they are phase shifted with an angle of $\theta=(360 \% \mathrm{~m}-1)$.

\section{SIMULATION RESULTS}

A simulation is carried out in MATLAB/Simulink for the proposed system. The switching frequency consists of two reference signals and triangular wave of $1.5 \mathrm{KHz}$. Figure 7 (a) determines the constant capacitor voltage obtained across the dc link across each H-bridge inverter. The MPPT using FLC tracks the MPPT very accurately and fastly. Figure 7(b) showsthe active power obtained at the grid and it is 550W. Figure 8(a) shows the balanced three phase grid current. It shows with the proposed control scheme a balanced three pase grid current is obtained. The three phase grid voltage is obtained in Figure 8(b). With the increase in levels it gives more sinusoidal waveform. Figure 9 gives the THD analysis of balanced three phase current. 


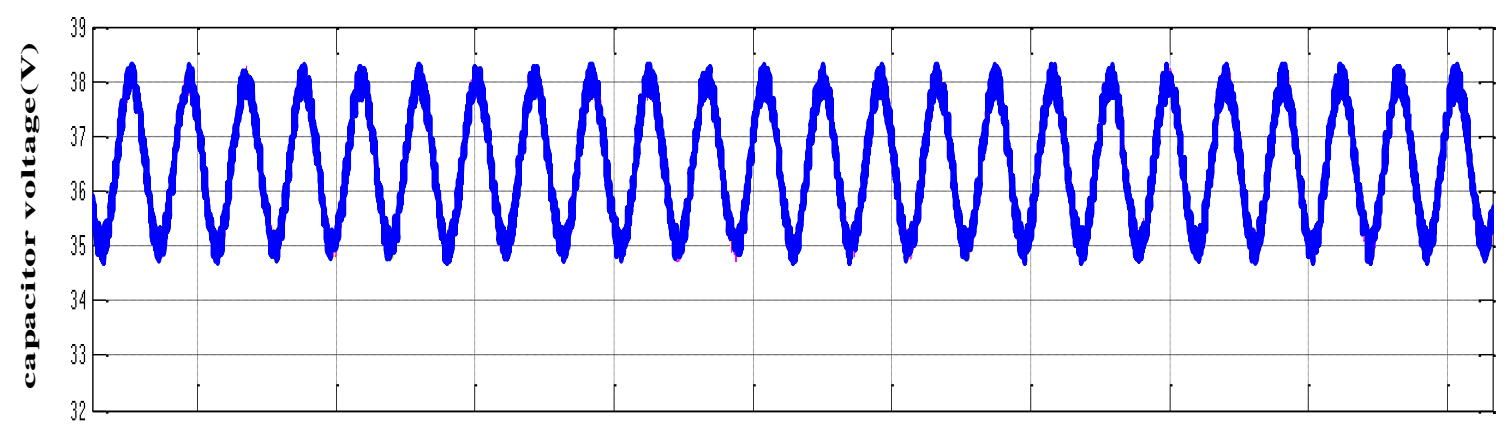

(a)

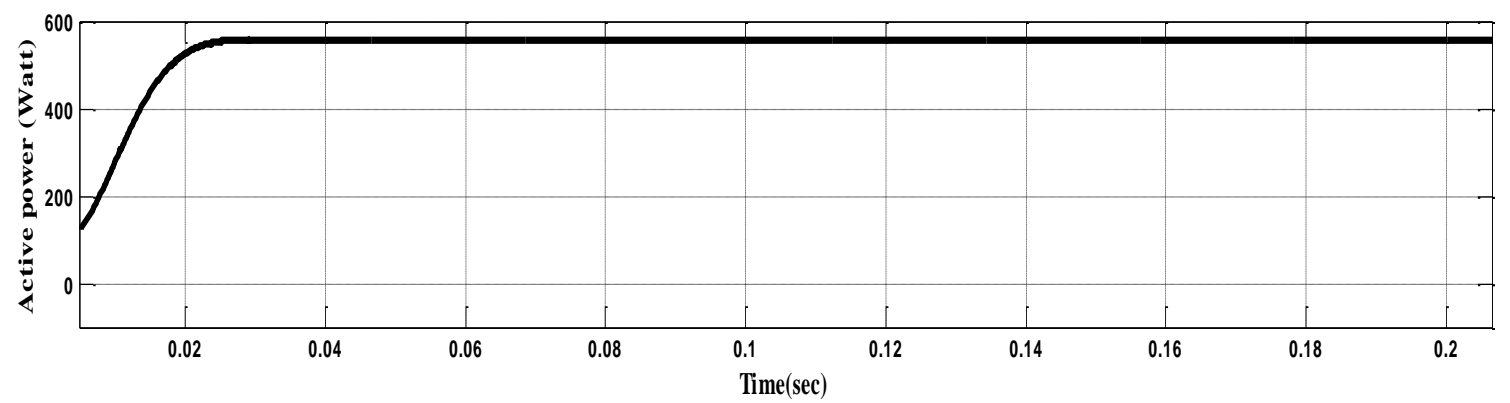

(b)

Figure 7. (a) DC link voltage obtained across different phases (b) Active power obtained from three phases

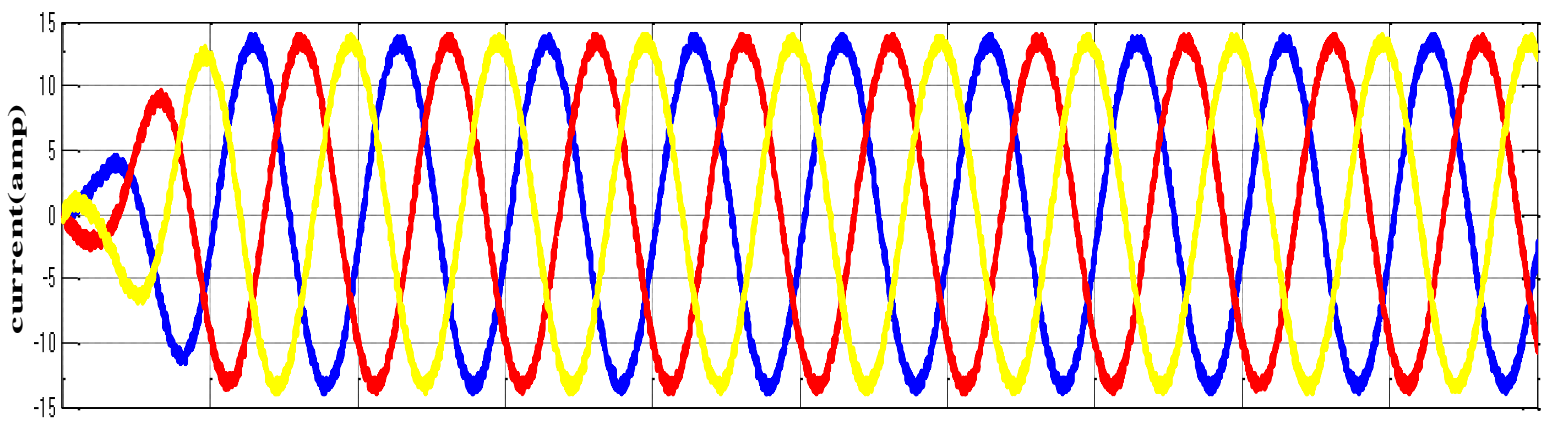

(a)

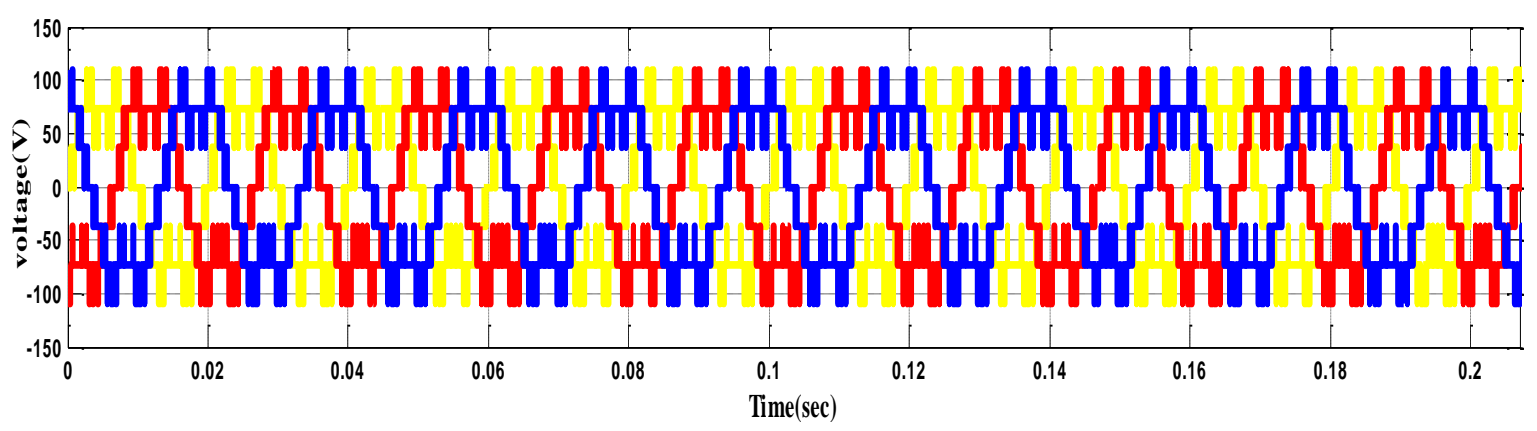

(b)

Figure 8. (a) Waveform of grid current (b) Grid voltage obtained 


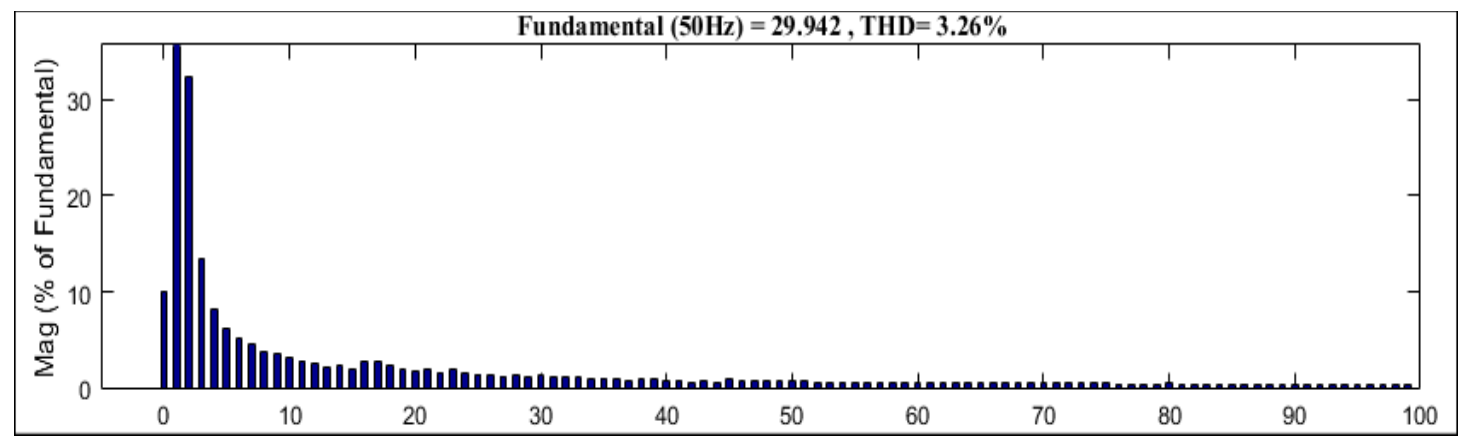

Figure 9. Harmonic spectrum analysis of grid current

\section{CONCLUSION}

A three phase grid tied cascaded H-bridge multilevel inverter is depicted in this paper. The proposed system is designed first and simulated in MATLAB/Simulink. It shows the mentioned fuzzy MPPT controller provides fast and better response from the other conventional methods. A digital PI controller is designed to maintain the balanced grid current under varying environmental conditions. The THD analysis of grid current is also obtained and it shows that with this proposed control strategy the obtained grid current has less THD that is specified by the IEEE-519 standard.

\section{REFERENCES}

[1] Rahnamaei A, Salimi M. A Novel Grid Connected Photovoltaic System. Bulletin of Electrical Engineering and Informatics (BEEI). June 2016; 5(2): 133-143.

[2] Panigrahi S, Thakur A. Current trends in power electronics for wind and solar energy conversion systems. International Conference on Power and Embedded Drive Control (ICPEDC), Chennai. 2017: 242-247.

[3] Gupta K. K, Ranjan A, Bhatnagar P, Sahu L. K, Jain S. Multilevel Inverter Topologies with Reduced Device Count: A Review. IEEE Transactions on Power Electronics. 2016; 31(1):135-151.

[4] Castillo R, Diong B, Biggers P. Single-phase hybrid cascaded H-bridge and diode-clamped multilevel inverter with capacitor voltage balancing. IET Power Electronics. 2018; 11(4): 700-707.

[5] Dorahaki S. A Survey on Maximum Power Point Tracking Methods in Photovoltaic Power Systems. Bulletin of Electrical Engineering and Informatics (BEEI). 2015; 4(3): 169-175.

[6] Sera D, Mathe L, Kerekes T, Spataru S. V, Teodorescu R. On the Perturb-and-Observe and Incremental Conductance MPPT Methods for PV Systems. IEEE Journal of Photovoltaics. 2013; 3(3): 1070-1078.

[7] Rakhshan M, Vafamand N, Khooban M. H, Blaabjerg F. Maximum Power Point Tracking Control of Photovoltaic Systems: A Polynomial Fuzzy Model-Based Approach. IEEE Journal of Emerging and Selected Topics in Power Electronics. 2018; 6(1): 292-299.

[8] Huang Q, Wang M, Yu W, Huang A. Q. Power-weighting-based multiple input and multiple output control strategy for single-phase PV cascaded H-bridge multilevel grid-connected inverter. IEEE Applied Power Electronics Conference and Exposition (APEC), Charlotte, NC. 2015: 2148-2153.

[9] Kumar N, Saha T. K, Dey J. Sliding-Mode Control of PWM Dual Inverter-Based Grid-Connected PV System: Modeling and Performance Analysis. IEEE Journal of Emerging and Selected Topics in Power Electronics. 2016; 4(2): 435-444.

[10] Villalva M. G, Gazoli J. R, Filho E. R. Comprehensive Approach to Modeling and Simulation of Photovoltaic Arrays. IEEE Transactions on Power Electronics. 2009; 24(5): 1198-1208.

[11] Singh O, Rajput S. K. Mathematical modelling and simulation of solar photovoltaic array system. International Conference on Research Advances in Integrated Navigation Systems (RAINS) Bangalore. 2016: 1-5.

[12] Bouchafaa F, Beriber D, Boucherit M. S. Modeling and simulation of a gird connected PV generation system with MPPT fuzzy logic control. 7th International Multi- Conference on Systems, Signals and Devices, Amman. 2010: $1-7$.

[13] Rodriguez J, Lai J. S, Peng F. Z. Multilevel inverters: A survey of topologies, controls, and applications. IEEE Trans. Ind. Electron. 2002; 49(4): 724-738.

[14] Selvaraj J, Rahim N. A. Multilevel Inverter for Grid-Connected PV System Employing Digital PI Controller. IEEE Transactions on Industrial Electronics. 2009; 56(1): 149-158.

[15] Sahoo S. K, Bhattacharya T. Phase-Shifted Carrier-Based Synchronized Sinusoidal PWM Techniques for a Cascaded H-Bridge Multilevel Inverter. IEEE Transactions on Power Electronics. 2018; 33(1): 513-524. 